within their working day. Musicians from the orchestra have become aware of the hospice services, and have come in to play within the hospice itself. More formal evaluation of the impact of the experience on our participants is being developed.

Conclusion Orchestra Outreach is a way of offering patients, their families and carers a 'normalising' experience they can share. The orchestra are keen to continue their partnership with the hospice. A full evaluation of the project is recommended.

'Music produces a kind of pleasure which human nature cannot do without', Confucius.

\section{P-128 EVERY BREATH YOU TAKE: TRACHEOSTOMY VENTILATION IN PAEDIATRIC PALLIATIVE CARE}

Elli Rushton, Chris Viney. Wessex Children's Hospice Trust, Winchester, UK

\subsection{6/bmispcare-2019-HUKNC.151}

Background Children's palliative care is changing. Medical and technological advances enable an increasing number of children with life limiting conditions to survive on long term ventilation (LTV) via tracheostomy. University Hospital Southampton identified that children spend months in hospital awaiting home adaptations and establishment of a care package. This can have a significant impact on family life.

\begin{tabular}{llll}
$\begin{array}{l}\text { Abstract P-128 Table 1 } \\
\text { year at University Hospital Southampton }\end{array}$ & Number of LTV patients started each \\
\hline 2007 & 4 & 2013 & 21 \\
2008 & 3 & 2014 & 35 \\
2009 & 12 & 2015 & 43 \\
2010 & 11 & 2016 & 45 \\
2011 & 22 & 2017 & 48 \\
2012 & 23 & & \\
\hline
\end{tabular}

\section{Aims}

- To set up a unit for tracheostomy ventilated children within a children's hospice in partnership with the hospital, providing accommodation and nursing support for three children and families preparing for discharge home;

- Facilitate care of the child outside the hospital environment.

Methods

October 2016 to March 2017:

- Literature review;

- Partnership working with respiratory team;

- Agreed practice framework.

March 2017 to October 2017:

- Collaboration with specialist paediatric respiratory, and hospice palliative care teams;

- Workforce planning;

- Development of clinical pathways, governance, policies;

- Practice Education team develop LTV Study day, Competency Framework, ongoing review of clinical practice;

- Preparation of children and families for transfer from High Dependency Unit to hospice.
Results

November 2017:

- Admission of first tracheostomy ventilated child and family from HDU to unit;

- Resident for six months, successful weaning off day time ventilation.

July 2018:

- Admission of second child from HDU to unit;

- Resident four months, discharged on weaning programme;

- No complications or significant infections acquired by either child;

- Saved hospital bed days: 308;

- Staff competency increased from $47 \%$ to $93.5 \%$;

- Maintained good relationship with families.

Conclusion With robust education and governance, tracheostomy ventilated children can be safely cared for in a hospice environment. Parents reported the environment had a positive impact on family dynamics and improved childrens' physical and emotional well being.

\section{P-129 RECOGNISING DELIRIUM IN A PALLIATIVE CARE INPATIENT UNIT-ARE WE DOING ENOUGH?}

Sam Matthews, Rebecca Kean, Emer Mckenna, Salman Rafique Chatha. Douglas Macmillan Hospice, Stoke on Trent, Staffordshire

\subsection{6/bmjspcare-2019-HUKNC.152}

Background As a hospice we had introduced several initiatives to improve care of inpatients including sepsis awareness and the butterfly scheme which support patients who are confused without a formal diagnosis of dementia. Amongst palliative inpatients, a recent systematic review found that occurrence rates varied by up to $30 \%$ on admission, during admission, and the weeks and hours before death.

Aim We wanted to understand within our inpatient setting how frequently confusion is an issue on admission, how we are detecting delirium and are we looking for reversibility. Between one-third and one-half of delirium cases are potentially reversible.

Results We conducted a baseline retrospective audit of admission records over March 2019. 39 notes meet criteria where patient had not died within 24 hours of admission. $25 \%$ (10) remained unconfused within 24 hours before death. $7 \%$ (3) were confused on admission but were reversed with medication changes and interventions such as antibiotics or oxygen suggesting delirium a feature of agitation and successfully went home. None of these patients has underlying brain pathology. 41\% (16) who were confused died despite a small improvement in confusion. Delirium and accurately describing acute confusion was sporadic. Only one patient who remained confused from admission was discharged.

Outcome We implemented a lunch and learn mandatory programme for all clinical staff and introduced the 4AT tool and delirium checklist as first steps to earlier recognition and identification of reversible factors. We have also created a family and patient leaflet explaining what delirium is and how it can be managed. 
Conclusion There is evidence of change in practice already within the nursing staff approach to monitoring and managing confused patients. We plan to re-audit in October and introduce the same learning programme for all community staff especially Hospice at Home healthcare assistants to enhance detection of delirium within the home setting.

\section{P-130 IMPLANTABLE DEFIBRILLATOR DEACTIVATION: ATTITUDES AND KNOWLEDGE IN HEALTHCARE PROFESSIONALS}

1,2Lauren Brice, 'Susan Powell. 'University Hospitals Birmingham, Birmingham, UK; ${ }^{2}$ Marie Curie Hospice West Midlands, Solihull, UK

10.1136/bmispcare-2019-HUKNC.153

The prevalence of implantable defibrillator devices is increasing in the UK. These devices may prevent sudden cardiac death from arrhythmias, however, they do not alter disease trajectory in chronic conditions. Patients approaching end of life are predisposed to arrhythmias. This may lead to patients with implantable defibrillators receiving a shock in their final days of life which could be distressing and inappropriate when comfort is the priority. Despite this, elective deactivation of defibrillator devices is infrequently discussed and is often left until the last days of life.

An online survey of healthcare professionals was performed to assess attitudes toward device deactivation and knowledge of local procedures for deactivation. A total of 30 responses were collected. Responders were doctors and specialist nurses with variable clinical experience from a variety of specialties.

Only 50\% of individuals were able to correctly identify all implantable devices that contained a defibrillator component. Thirteen individuals felt they knew the protocol for arranging a planned deactivation of devices, however, only six individuals were able to correctly describe the process.

$77 \%$ of individuals felt that deactivation should be discussed as soon as possible in a patient identified as being in their last year of life and $73 \%$ felt that anyone involved in the patient's care should be able to have this discussion. In spite of this, when asked to rank their confidence having the conversation, the mean score was 54/100.

The most selected appropriate timescale between defibrillator deactivation and death from a chronic disease was months and $87 \%$ of individual felt that deactivation should occur in the outpatient setting or community rather than during an acute admission.

In summary, healthcare professionals felt that deactivation should be discussed and planned at the earliest opportunity, however, many did not feel confident having this discussion and were unable to identify all devices containing defibrillators or describe the local procedure for deactivation.

\section{P-131 INFORMATION WITH IMPACT: ANALYSIS OF FEEDBACK ABOUT WHAT TO EXPECT AT END OF LIFE ONLINE INFORMATION}

Amy Evans, Kim Bonnar, Morven Masterton. Marie Curie, London, UK
Background The Ambitions for Palliative and End of Life Care framework highlights the importance of information in supporting people affected by death and dying (National Palliative and End of Life Care Partnership, 2015). All information should meet high standards. Ensuring users can provide feedback is a core principle of the NHS Information Standard.

Aim A national charity sought feedback on its What to expect at end of life online information. The aim was to assess the usefulness of the information and to understand what worked, possible improvements, and any impact the information had on end of life experiences.

Method In March 2019 a survey was embedded on three web pages, which included two questions:

1. How useful did you find this page?

2. Please tell us why.

Results 106 responses were received. 88\% found the pages either Very useful (74\%) or Useful (14\%). Thematic analysis of the open text boxes identified these themes:

- Informative;

- Helped them prepare for future;

- Easy to understand;

- Sensitive/compassionate;

- Confidence/reassurance about actions.

The qualitative open text boxes provided examples of the impact the information can have, including:

'Having some idea of the indications of imminent death will help us to organise our time to ensure we're there when his time is approaching.'

'Although the situation is harrowing, I think part of the anxiety comes from fear of the unknown. This diminishes when we have the small comfort, of knowing what to expect.'

Six respondents felt there were gaps in the content, including how to deal with emotions.

Conclusion This research tells us that most respondents found the information useful, and that it has the potential to positively impact on people's end of life experiences.

\section{P-132 DRY MOUTH IN PALLIATIVE CARE, HOW ESSENTIAL OIL MOUTHWASH CAN HELP}

Alison Bailey. Weston Hospicecare, Weston Super Mare, UK

\subsection{6/bmjspcare-2019-HUKNC.155}

Background Dry mouth is extremely common in palliative care affecting 62\% of patients (Otukoya \& Doshi, 2018). To try and improve this for our patients a quality improvement programme (QIP) using essential oil mouthwash was agreed.

Aim To improve dry mouth for palliative patients using an evidence-based essential oil mouthwash, working in collaboration with medical and complementary therapy staff.

Method

- Precautions of using essential oils orally were identified;

- Patients were assessed for their suitability to use essential oils;

- All essential oils needed a safety data sheet and mouthwashes were clearly labelled;

- Observational study was undertaken 2018-2019;

- Staff trained to select sample group using validated assessment tool for inclusions (Health Education England: mouth care matters programme), exclusions: ulcers, thrush, patient unable to rinse, sensitive to oils, using oxygen; 